
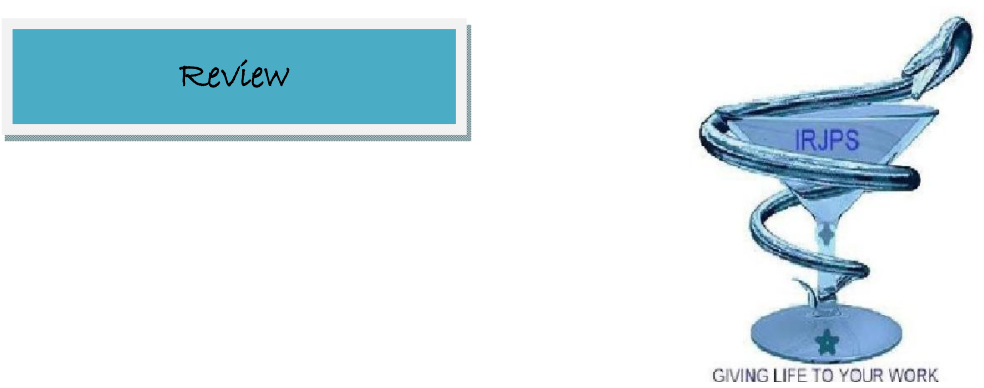

\title{
MEDICAL DEPRESSIVE DISORDER, ALZHEIMER'S, EPILEPSY AND THEIR CURRENT TREATMENTS AVAILABLE IN INDIA
}

\author{
Saleh Bin Ali Al-Ghamdi, Mohammad Yusuf* \\ College of Pharmacy, Taif University, Taif-Al- Haweiah-21974, Kingdom of Saudi Arabia
}

Submitted on: 08.08.16;

Revised on: 17.08.16;

Accepted on: 25.08.16

\begin{abstract}
Brain disorders are not confined to the western countries and their rate is increasing frequently in the Indian subcontinents, ranging from adolescents to adults. The key diseases i.e. Depression, Alzheimer's and Epilepsy are common and are predicted to upsurge in the future. Media and entertainment technologies may be the causative factors but still needs a lot of research. Conventional treatment is effective but with complementary ineligible side effects, which need an effective regimen guidelines for their use. The alternative therapeutic system is also an option to be augmented with the present therapeutic system but still needs a lot of regulation clearance. The present review deals with the current system and the best guidelines to be followed for the particular diseases.
\end{abstract}

KEY WORDS: Alzheimer's, Epilepsy, Depression, Treatment.

Corresponding Author: Mohammad Yusuf

Mobile +966540464942, +919990972899

Email: yusuf4682@gmail.com
Indian Research Journal of Pharmacy and Science; 10(2016) 737-750 Journal Home Page: https://www.irjps.in 


\section{INTRODUCTION}

A large population in India is suffering from brain disorders. ${ }^{1,2}$ In 1906 Dr. Alois Alzheimer, a German physician who had discovered Alzheimer's disease (AD) after watching an elderly patient died of an unknown mental illness. Later he proved it as a degenerative neurological disease. ${ }^{3}$ According to an estimation by the year 2020, approximately $70 \%$ of the world's population aged 60 will be suffering from this disease, among them $14.2 \%$ will prevail in India. ${ }^{4}$ Even epilepsy which was considered as a supernatural event, was thought as a form of a demonic possession. Around 50 million individuals suffering from epilepsy globally and most of them are the part of developing countries like India, which only comprises of about 10 million people. With limited knowledge and unappropriated treatment, people of India are facing a large treatment gap. ${ }^{5}$ On the other hand depression was called as melancholia and black magic was thought to be its causative agents. Its prevalence rates ranges from $7 \%$ to $12 \%$ in men and $20 \%$ to $25 \%$ in women, and leading mortality rates to 6 -fold, among it, $15 \%$ mortality is by suicide. ${ }^{6}$ These diseases have been treated with allopathic drugs for several years in the past and yet more drugs are needed to rectify. The present review deals with key diseases and their current treatments available in India. $^{7}$

\section{Depression and current therapy}

The lifetime existence of this disorder is as high as $20 \%$ in the common population worldwide in the ratio (male: female) 5:2. A large proportion becomes chronic and when to follow up to 5 and 10 years found $12 \%$ and $7 \%$, respectively, were still depressed. ${ }^{8}$ After recovery patients found a high rate of recurrence, among them $75 \%$ of patients experienced major depression episode more than once within 10 years. ${ }^{9}$ Suicide is a considerable risk for mortality in depression, and the rate of suicide is found to be high among the age group of 15 to 24 years. ${ }^{10}$

\subsection{Pathophysiology of depression}

\subsubsection{Monoamine hypothesis}

Schildkraut proposed the catecholamine hypothesis of mood disorders in 1960. The deficiency of noradrenaline in definite brain tracks are linked with depression whilst an overabundance results in mania. These brain tracks are found in the brain stem, in the locus coeruleus, and project to many areas of the brain as well as the limbic system which is essential in controlling emotions. ${ }^{11}$

Evidence for noradrenaline depletion in depression also comes from the following observations:

1. Levels of metabolites of noradrenaline in urine and CSF are low in depressed individuals

2. Increased densities of certain noradrenaline receptors in the cortex of depressed suicide victims.

3. This pattern of 'up-regulation' occurs when the level of neurotransmitter in synapses is abnormally low and is a compensatory mechanism to pick up whatever signals are available.

4. Drugs which selectively block noradrenaline reuptake such as reboxetine, increase noradrenaline in synapses and are effective antidepressants in many people. ${ }^{12}$

\subsubsection{Serotonin Hypothesis}

Synaptic depletion of serotonin is implicated in depression. It may be that defects in neuronal circuits using serotonin could dampen noradrenaline signaling. Serotonin producing neurones project from the raphe nuclei in the brain stem to many regions of the brain including those that secrete noradrenaline. However, serotonin may also be more directly responsible for depression since there are serotonin producing neurons extending into areas of the brain thought to be involved in depressive symptoms these include the amygdala which is involved in appetite, libido, and sleep. ${ }^{13}$

Evidence for serotonin depletion:

1. Tricyclic antidepressants produce many effects in the brain, including a decrease in serotonin reuptake and a consequent rise in serotonin levels in synapses.

2. Selective serotonin reuptake inhibitors (SSRI's) such as prozac, block the reuptake of serotonin into the presynaptic 
neuron, they are hugely significant in the treatment of depression.

\subsubsection{Endocrine processes in depression}

A variety of hormonal abnormalities, such as altered levels of Cortisol, growth hormone $(\mathrm{GH})$, or thyroid hormones, indicate the existence of endocrine disturbances, especially dysfunctions in the hypothalamus pituitary-adrenal (HPA) axis and/or the regulation of thyroid function. The consistent finding that a significant subpopulation of depressed patients hypersecrete Cortisol during the depressed state but not after recovery ${ }^{14}$ led to intensive investigation and analysis of the HPA system. The observations include hypersecretion of hypothalamic corticotropin-releasing hormone $(\mathrm{CRH})$ and inadequate glucocorticoid feedback, increased Cortisol levels, and impaired suppression of the HPA axis in response to exogenous glucocorticoid administration. A more refined analysis recently led to formulation of the concept that impaired corticosteroid receptor signaling is a key mechanism in the pathogenesis of depression. ${ }^{15}$

\subsubsection{Neuroimmune mediators}

The immune system is a key mediator of brain-body interactions. Cytokines influence various CNS functions that are dysregulated in major depression, such as sleep, food intake, cognition, temperature, and neuroendocrine regulation. ${ }^{16}$ Experimental administration of interleukin-1 (IL-1) into the CNS produces stress-like effects on behavior, monoamine transmitters, HPA axis activity, and immune function; IL-1 is also a regulator of the 5-HT transporter gene. Another hint to the link between immune system and mood came from observations that a large number of previously psychiatrically healthy individuals treated with exogenous cytokines such as interleukin-2 (IL-2) and interferon- $\alpha$. (IFN- $\alpha$ ) develop depression-like symptoms, such as depressed mood, increased somatic complaints, and stress reaction, cognitive impairment, and difficulties with motivation and flexible thinking. ${ }^{17}$ The fact that these are transient alterations, which disappear after termination of therapy, implies that cytokines may play a causal role in producing these symptoms.

\subsubsection{Neurotrophins and depression}

One hypothesis for the pathophysiology and treatment of depression involves adaptation or plasticity of neuronal systems. Depression could thus result from an inability to make the appropriate adaptive responses to stress or other aversive stimuli, and antidepressants may act by correcting this dysfunction or by directly inducing the appropriate adaptive responses. ${ }^{18}$ The neurotrophic factors are among the growth factors that have been studied for their role in the adult nervous system. Of these endogenous proteins, brain derived neurotrophic factor (BDNF) and neurotrophin-3 (NT-3) have been shown to promote the function and growth of 5-HTcontaining neurons in the adult brain. Chronic, but not acute, infusions of these substances have impressive effects on serotonergic neuron growth and regeneration, and further induced sprouting of 5-HT nerve terminals. ${ }^{19}$

\subsection{Sign and symptoms}

According to the criteria of the Diagnostic and Statistical Manual of Mental Health, Fourth Edition (DSM-IV). Depression is a major disorder that affects a large number of population all over the world. It is not barred to age and can occur at any stage of life causes severe behavioral changes and distress in normal life. If left untreated, can be deadly. The main psychopathological symptoms involved are anhedonia, low or depressed mood, and low energy or fatigue. Other symptoms included are feelings of guilt, sleep, and psychomotor disturbances, suicidal tendencies, low self-esteem with autonomic and gastrointestinal distress. Depression is heterogeneous disorder and a complex phenomenon of many subtypes and multiple etiologies. It concerned with progressive mood disturbances with or without psychotic features and influence with other somatic and psychiatric disorders. $^{20}$

\subsection{Pharmacological treatment of depression}

The first-generation antidepressants, the tricyclic antidepressants (TCAs) and MAO inhibitors (MAOIs), increase the concentrations of 5-HT and/or $\mathrm{NE}$ and are effective in alleviating the symptoms of depression. Although both types of drugs have been used with great success for many years, there are 
several undesirable side effects that limit their application. TCAs acts on many other transmitter systems in the CNS and periphery, e.g., the histaminergic or acetylcholinergic systems, ${ }^{21}$ leading to sedation, hypotension, blurred vision, dry mouth, and other unwanted effects. In addition, TCAs may be life -threatening and fatal in overdose, especially due to their effects on the cardiovascular system. ${ }^{22}$ Also, the irreversible MAOIs have their own problems, such as an interaction with tyramine (the so-called "cheese effect"), which causes potentially lethal hypertension. The development of newer antidepressants has aimed to improve the safety and tolerability of the TCAs and reuptake inhibitors, and selectivity for a single monoamine seemed to be the key to this goal. Since the introduction of fluoxetine as the first selective serotonin reuptake inhibitor (SSRI), a great number of similarly acting drugs have followed and SSRIs are now applied in the treatment of several psychiatric disturbances, such as anxiety, panic, or obsessive-compulsive disorder, where altered serotonergic transmission is assumed. ${ }^{21}$ Because preclinical and clinical studies have shown that chronic stimulation of the 5-HT system also affects the NE system and vice versa, ${ }^{23}$ there has been renewed interest in the role of neurotransmitters other than serotonin. The development of the newest generation of antidepressants, including reboxetine (a selective NE-reuptake inhibitor), venlafaxine (a dual reuptake inhibitor), or the multiple receptor-acting substances mirtazepine, nefazodone, bupropion, and trazodone, may positively influence therapeutic potentials with reduced incidence of side effects due to reduced affinities for other systems. Interestingly, one drug, tianeptine, shows a quite atypical mechanism, namely an increase in 5-HT uptake, but most probably this substance predominantly counteracts stress effects in the hippocampus. ${ }^{24} \mathrm{~A}$ treatment guideline from APA and neurostar through TMS therapy is shown in Figure 1.

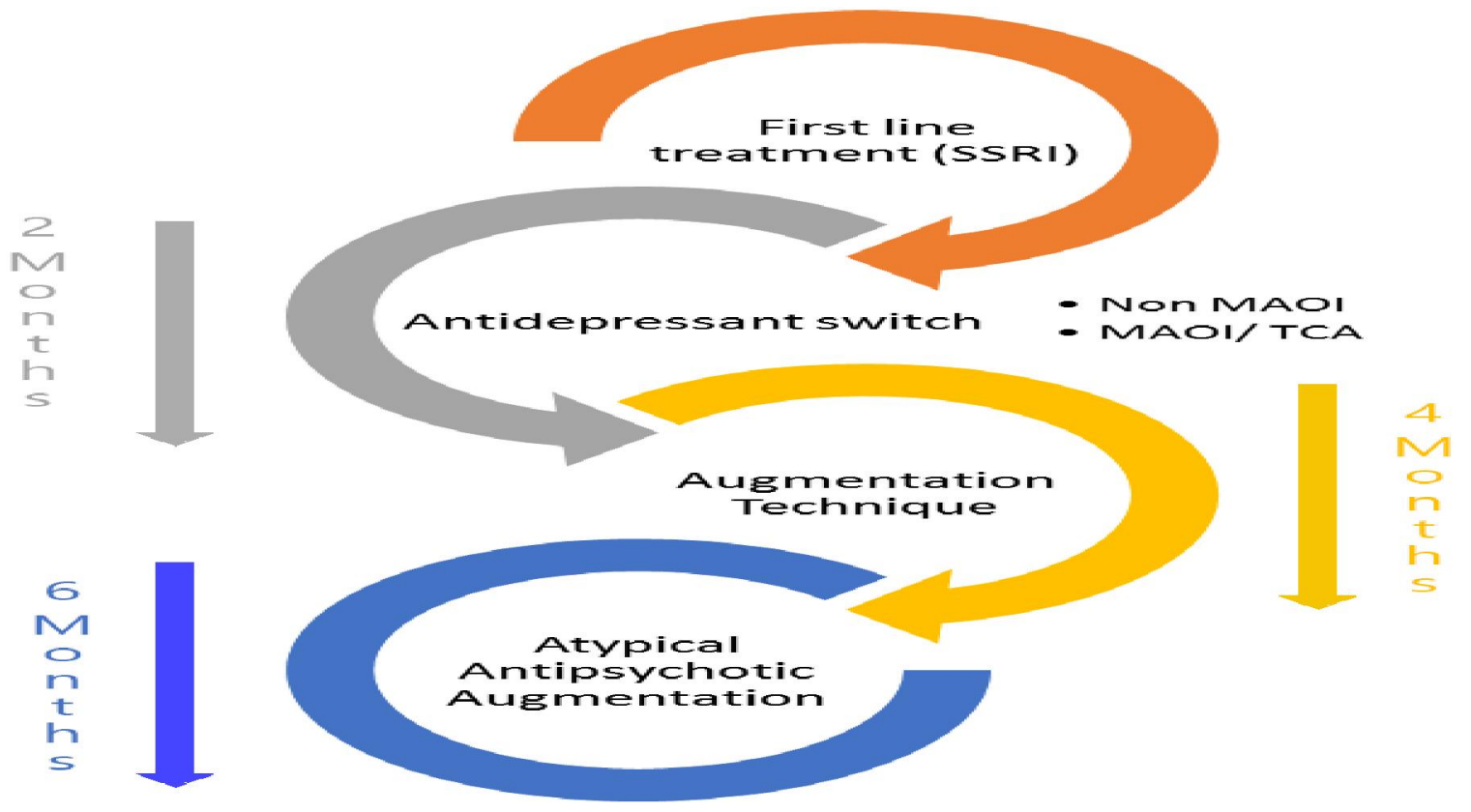

Figure 1. Treatment guideline for depression based on 2010 APA guidelines and neurostar TMS Therapy. 
Table 1. Chemical antidepressant Drugs approved by the FDA

\begin{tabular}{llllll}
\hline Generic & Drug Class & $\begin{array}{l}\text { Starting } \\
\text { Dose(mg/d) }\end{array}$ & $\begin{array}{l}\text { Therapeutic } \\
\text { Range(mg/d) }\end{array}$ & $\begin{array}{l}\text { Half- } \\
\text { Life (h) }\end{array}$ & Schedule \\
\hline Amitriptyline & TCA & 25 & $150-300$ & $12-24$ & qhs \\
Amoxapine & NSRI & 100 & $200-300$ & $8-30$ & Bid \\
Bupropion & NDRI & 75 & $300-450$ & 20 & Tid \\
Citalopram & SSRI & 10 & $20-40$ & 35 & Qd \\
Desipramine & TCA & 25 & $150-300$ & $21-23$ & Qd \\
Doxepin & TCA & 25 & $150-300$ & $17-51$ & qhs \\
Duloxetine & NSRI & 20 & $30-60$ & 12 & Bid \\
Escitalopram & SSRI & 10 & $10-20$ & $27-32$ & Qd \\
Fluoxetine & SSRI & 10 & 20 & $4-16 \mathrm{~d}$ & Qd \\
Imipramine & TCA & 25 & $150-300$ & $11-25$ & qhs \\
1-Deprenyl & MAOI & 6 & 12 & 10 & Qd \\
Maprotiline & NRI/TetraCA & 25 & 150 & $43-90$ & qhs \\
Mirtazapine & Other & 15 & $15-45$ & $20-40$ & qhs \\
Nefazodone & Other & 200 & 600 & $2-4$ & bid-tid \\
Nortriptyline & TCA & 10 & $75-150$ & $16-44$ & qd \\
Paroxetine & SSRI & 10 & $20-40$ & 24 & qd \\
Phenelzine & MAOI & 15 & $45-90$ & 12 & bid-tid \\
Protriptyline & TCA & 5 & $15-30$ & $60-90$ & tid \\
Sertraline & SSRI & 50 & $50-200$ & 26 & qd \\
Tranylcypromine & MAOI & 10 & $20-60$ & $4-8$ & bid-tid \\
Trazodone & Other & 100 & $300-600$ & $3-9$ & bid-tid \\
Trimipramine & TCA & 25 & & $11-23$ & qhs \\
Venlafaxine & NSRI & 25 & $225-375$ & $5-11$ & tid \\
\hline & & & & & \\
\hline
\end{tabular}

\section{ALZHIEMER'S DISEASE AND CURRENT THERAPY}

Originally described by Alois Alzheimer in 1907, Alzheimer's disease (AD) has emerged as the most common type of dementia in the elderly today. ${ }^{25}$ Although the definitive diagnosis of $\mathrm{AD}$ requires histologic confirmation, in the absence of a readily discernible cause, the clinician may establish the diagnosis ante mortem, with a fair degree of certainty, based on the clinical findings of a gradually progressive cognitive decline that results in the loss of memory, language skills, activities of daily living, and executive function. ${ }^{26}$

\subsection{PATHOPHYSIOLOGY}

The classic neuropathologic findings in $\mathrm{AD}$ include amyloid plaques, neurofibrillary tangles, and synaptic and neuronal cell death. Granulovacuolar degeneration in the hippocampus and amyloid deposition in blood vessels might also be seen on tissue examination.

\subsubsection{Amyloid Plaques}

Although amyloid plaques or senile plaques may be classified further according to their composition, all contain forms of $\beta$-amyloid protein (A $\beta)$. $A \beta$ is a 39to 42 -amino acid peptide that is formed by the proteolytic cleavage of $\beta$-amyloid precursor protein (APP) and is found in extracellular deposits throughout the central nervous system (CNS). ${ }^{27} \mathrm{~A} \beta$ is believed to interfere with neuronal activity because of its stimulatory effect on production of free radicals, resulting in oxidative stress and neuronal cell death. ${ }^{28}$

\subsubsection{Neurofibrillary Tangles}

Neurofibrillary tangles are paired helical filaments composed of tau protein, which in normal cells is essential for axonal growth and development. 
However, when hyperphosphorylated, the tau protein forms tangles that are deposited within neurons located in the hippocampus and medial temporal lobe, the parietotemporal region, and the frontal association cortices, leading to cell death. ${ }^{29}$

\subsubsection{Neuron and Synapse Loss}

Areas of neuronal cell death and synapse loss are found throughout a distribution pattern similar to that of the neurofibrillary tangles. ${ }^{30}$ The death of cholinergic neurons in the basalis nucleus of Meynert leads to a deficit in acetylcholine (Ach), a major transmitter believed to be involved with memory. ${ }^{31}$ In addition, loss of serotoninergic neurons in the median raphe and adrenergic neurons in the locus ceruleus lead to deficits in serotonin and norepinephrine, respectively. ${ }^{32}$

\subsubsection{Chromosomal Mutations}

Genetic mutations in chromosomes 21,14 , and 1 have been shown to cause familial early-onset AD. Inherited in an autosomal-dominant pattern, the chromosomal mutations account for less than $5 \%$ of all cases and result in the overproduction and deposition of $A \beta$. Chromosome 21, which codes for APP, was first evaluated for an association with AD when Down syndrome patients with the trisomy 21 aberration were observed to develop dementia in the fourth decade. Mutations in presenilin 1 (PS-1) on chromosome 14 and presenilin 2 (PS-2) on chromosome 1 also cause $\mathrm{AD}$ and are responsible for the majority of familial early-onset cases. ${ }^{33}$

\subsubsection{Inflammation}

The exact role of inflammation in the pathogenesis of $\mathrm{AD}$ is still controversial. Although some studies have been able to demonstrate the presence of activated microglia (a marker of the brain's immune response) in patients with probable $\mathrm{AD}$, a number of prospective clinical trials evaluating the use of drugs targeting various aspects of the immune system such as prednisone, hydroxychloroquine, and selective COX-2 inhibitors have been able to demonstrate only marginal benefits at best. ${ }^{34}$
Although some studies have suggested a neuroprotective role for nonsteroidal antiinflammatory drugs, a recent large study of 351 patients revealed that these medications did not slow progression and cognitive decline in established mild-to-moderate Alzheimer's disease. ${ }^{35,36}$

\subsection{Signs and symptoms}

$\mathrm{AD}$ is a progressive dementia with memory loss as the major clinical manifestation. Although short-term memory impairment is often the manifesting symptom, remote memory loss also appears to be affected over time. Another important feature of $\mathrm{AD}$ is the disturbance of language. Initially, AD patients might search for words when naming objects or while engaged in a simple conversation. But with progression of the disease, the language difficulties evolve into an inability to communicate as the patient struggles with a markedly limited vocabulary, nominal aphasia, and defects in verbal comprehension. ${ }^{37}$

Other cortical signs and symptoms such as apraxia, acalculia, and visio-spatial dysfunction may become apparent over the course of the disease. With the development of apraxia, patients lose the ability to carry out such simple tasks as combing their hair or turning on a water faucet. Acalculia may become evident when the patient is no longer able to maintain a checkbook or household accounts. Visio-spatial abnormalities can be seen as patients become disoriented with their body position in space. ${ }^{37}$

Behavioral problems emerge throughout the various stages of the disease. Mood disturbances such as depression, anxiety, or apathy may be present early on in $\mathrm{AD}$, whereas delusions, hallucinations, and psychosis can be prominent in later stages. In addition, aggression and inappropriate sexual behavior can be particularly problematic for the caregiver. ${ }^{38}$

In advanced stages of $\mathrm{AD}$, patients might exhibit extrapyramidal signs such as tremor and gait disturbance, frontal lobe release phenomena, urinary incontinence, and myoclonus. Seizures can also be seen in some patients with late-stage disease. Patients 
with end-stage AD almost invariably enter a vegetative state when all cognitive activity ceases. ${ }^{39}$

\subsection{Treatments of Alzheimer's}

\subsubsection{Management of Cognition}

The major issues in treating $\mathrm{AD}$ are the improvement of memory and cognition and the delay of disease progression. $^{40}$ At present, there are no proven medications that cure or slow progression of Alzheimer's disease. Temporary improvements in cognition and behavior can be seen with the two existing drug classes of cholinesterase inhibitors and $N$-methyl-d-aspartate (NMDA) receptor antagonists. $^{41}$

The three-cholinesterase inhibitors, as well as the NMDA receptor antagonist memantine, are listed in table 2. The new patch formulation of rivastigmine (Exelon) allows the convenience of once-daily administration, with a marked decrease in the common gastrointestinal (GI) side effects seen with the cholinesterase inhibitors. Efficacy appears to be similar among the cholinesterase inhibitors. The only reported differences are the dosing schedule and sideeffect profile of each individual drug. ${ }^{42}$

\subsubsection{Management of Noncognitive Symptoms}

Behavioral disturbances in $\mathrm{AD}$ may also be treated pharmacologically with both traditional and atypical neuroleptics. Although haloperidol can be effective, the atypical antipsychotics, which include risperidone, quetiapine, and olanzapine, may be better tolerated than traditional agents. There is not enough evidence to support the use of benzodiazepines, lithium, and anticonvulsants for the treatment of psychosis in patients with $\mathrm{AD}^{43}$ Special care units within long-term care facilities are another consideration; some studies have shown a reduced need for antipsychotics and physical restraints as well as a decrease in behavioral disturbances in $\mathrm{AD}$ patients who reside there. ${ }^{43}$ Psychosocial intervention for the caregiver is also an integral part of managing patients with AD. Education, support groups, and respite care services are should be suggested to family members. An age wise diagnosis and treatment is shown in Figure 2.

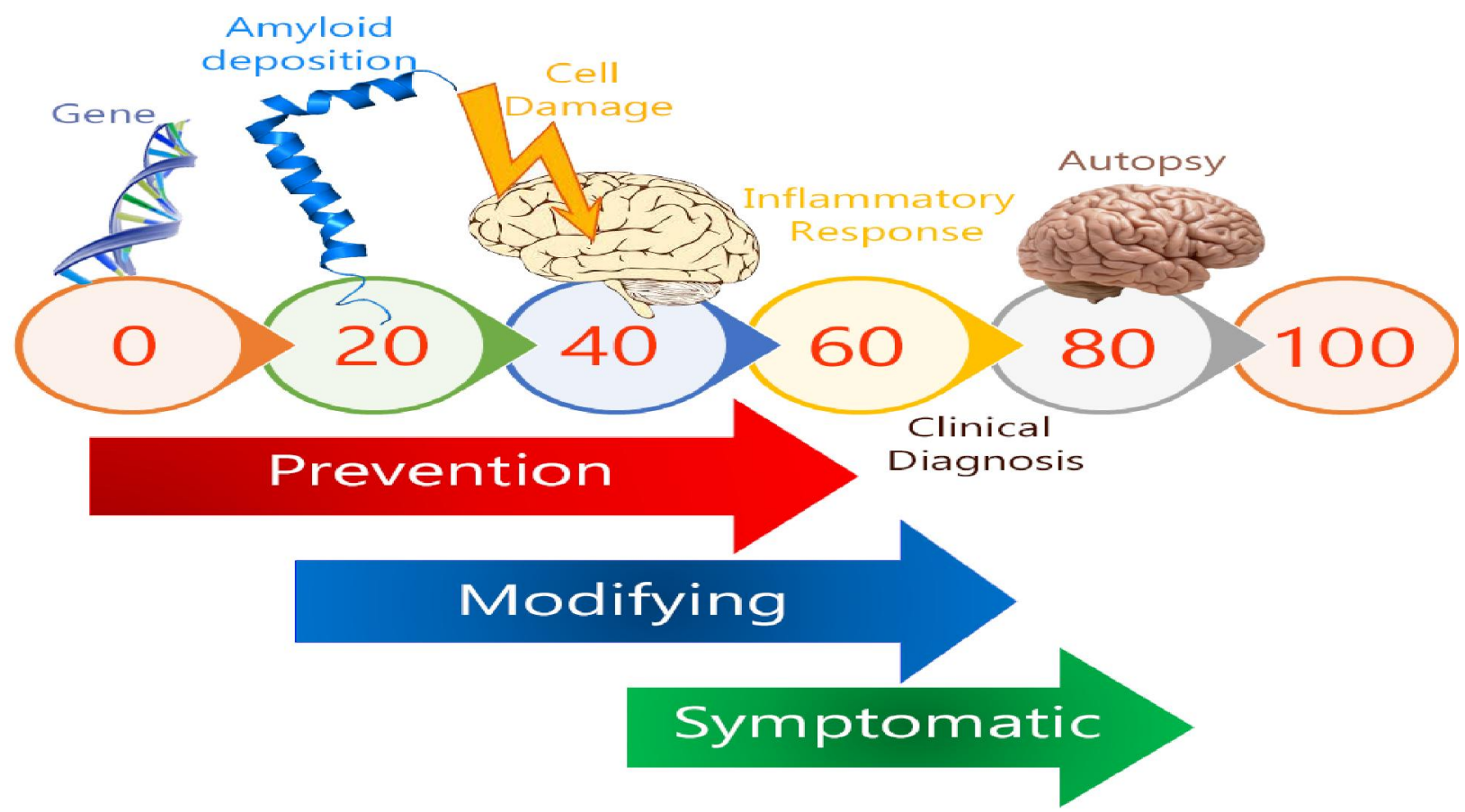

Figure 2. Alzheimer's disease Diagnosis and treatment in ages from 0-100 years 
Table 2. Drug Therapy for Alzheimer's disease

\begin{tabular}{|c|c|c|c|}
\hline & Class & Drug & Dose \\
\hline \multirow[t]{3}{*}{1} & Acetylcholinesterase Inhibitors & Donepezil & $\begin{array}{l}5 \mathrm{mg} \text { once daily, can } \\
\text { increase to } 10 \mathrm{mg} \text { daily } \\
\text { after } 4-6 \mathrm{wk}\end{array}$ \\
\hline & & Rivastigmine tartrate & $\begin{array}{l}\text { Pill: } 1.5 \mathrm{mg} \text { bid } \\
\text { initially, then titrate by } \\
1.5 \mathrm{mg} \text { bid every } 2 \mathrm{wk} \\
\text { up to } 12 \mathrm{mg} \text { daily } \\
\text { Patch: } 4.6 \text { and } 9.5 \mathrm{mg} \\
\text { patch size daily }\end{array}$ \\
\hline & & Galantamine & $\begin{array}{l}4 \mathrm{mg} \text { bid initially, then } \\
\text { titrate by } 4 \mathrm{mg} \text { bid } \\
\text { every } 4 \text { wk up to } \\
24 \mathrm{mg} \text { daily }\end{array}$ \\
\hline 2 & NMDA Receptor Antagonists & Memantine & $10 \mathrm{mg}$ bid \\
\hline
\end{tabular}

\section{EPILEPSY AND CURRENT TREATMENT}

Seizures result from paroxysmal and excessive electrical neuronal discharges in the brain that cause a variety of clinical manifestations. The term epilepsy is usually restricted to those cases with a tendency for recurrent seizures. The identification of a seizure as a symptom and not a disease diagnosis is an important distinction. Seizures are the clinical manifestation of epilepsy; the challenge is to identify the disease that explains the symptom. Often the underlying disease is epilepsy, but at other times it may be a nonepileptic disorder that causes symptoms that resemble an epileptic seizure. ${ }^{44}$

The term epilepsy encompasses a group of syndromes that vary in its associated pathology and seizure types. The diagnosis of the epileptic syndrome is one of the primary objectives undertaken when managing a patient with seizures. ${ }^{45}$

\subsection{Pathophysiology}

Two sets of changes can determine the epileptogenic properties of neuronal tissues. Abnormal neuronal excitability is believed to occur because of disruption of the depolarization and repolarization mechanisms of the cell (this is termed the excitability of neuronal tissue). Aberrant neuronal networks that develop abnormal synchronization of a group of neurons can result in the development and propagation of an epileptic seizure (this is termed the synchronization of neuronal tissue). ${ }^{46}$

A hyperexcitability of neurons that results in the random firing of cells, by itself, may not lead to the propagation of an epileptic seizure. Indeed, both normal and abnormal patterns of behavior require a certain degree of synchronization of firing in a population of neurons. Epileptic seizures originate in a setting of both altered excitability and altered synchronization of neurons. The excitability of individual neurons is affected by

- Cell membrane properties and the microenvironment of the neuron

- Intracellular processes

- Structural features of neuronal elements

- Interneuronal connections

The membrane properties and microenvironment of neurons, which maintain potential differences of electrical charge, are determined by selective ion 
permeability and ionic pumps. Excitatory neurotransmitters usually act by opening $\mathrm{Na}^{+}$or $\mathrm{Ca}^{2+}$ channels, whereas inhibitory neurotransmitters usually open $\mathrm{K}^{+}$or $\mathrm{Cl}^{-}$channels. The mechanism of action of certain anticonvulsant medications is by $\mathrm{Na}^{+}$or $\mathrm{Ca}^{2+}$ channel blockade, which likely prevents repetitive neuronal firing. Extracellular ionic concentrations also can contribute to neuronal excitability; for example, an increase in extracellular $\mathrm{K}^{+}$concentrations (such as in rapid neuronal firing or dysfunction of glia, which is mainly responsible for $\mathrm{K}^{+}$reuptake) causes membrane depolarization. ${ }^{47}$

Various intracellular processes are controlled by genetic information. Neuronal excitability can be preprogrammed by DNA-controlled effects on cell structure, energy metabolism, receptor functions, transmitter release, and ionic channels. The mechanisms that induce these changes, either phasic or long term, appear to be linked to ionic currents, especially $\mathrm{Ca}^{2+}$ influx. Intracellular $\mathrm{Ca}^{2+}$ mediates changes in membrane proteins to initiate transmitter release and ion channel opening; it also activates enzymes to allow neurons to cover or uncover receptor sites that alter neuronal sensitivity. Various plastic or persistent changes in excitability can result by influencing the expression of genetic information through $\mathrm{Ca}^{2+}$ influx. This may occur by selectively inducing genes to synthesize a protein for a specific reason. One example is the induction of the $c$ fos gene to produce the c-fos protein in neurons involved in an epileptic seizure by the administration of pentylenetetrazol. The exact effects of this coupling are not known, but it provides a means to study the effects of neuronal excitation on cell growth and differentiation as a model for epilepsy, learning, and memory. ${ }^{48}$

In regard to the structural features of neuronal elements in relation to epilepsy, the two primary regions of the brain that are involved in epilepsy are the cerebral neocortex and the hippocampus. In the neocortex, excitatory synapses are made primarily of the dendritic spines and shaft. The release of neurotransmitters at these sites gives rise to excitatory postsynaptic potentials. The inhibitory synapses are more prominent on the soma or proximal dendrites and give rise to inhibitory postsynaptic potentials. The placement of these synapses effectively prevents distal excitatory events from reaching the axon hillock. ${ }^{49}$ Alterations of neuronal morphology, either spontaneously or as a response to injury, could enhance excitability with either an actual increase in the number of excitatory synapses or a decrease in the number of inhibitory synapses. Such alterations could consist of reduced dendritic branching with excitatory synapses placed closer to the axon hillock, or loss of spines, allowing more excitatory synapses to occur directly on the shaft. Lesions in the neuronal cell body or tracts lead to degeneration of the axon terminal and a new terminal may sprout to make contact with the vacated postsynaptic membrane. This may, in turn, lead to an increase in the excitatory potential of the neuron. ${ }^{50} \mathrm{Ca}^{2+}$ currents that occur predominantly at the dendrites causing a high-amplitude prolonged depolarization that can evoke a rapid train of $\mathrm{Na}^{+}$action potentials (burst-firing of $\mathrm{Na}^{+}$), which is followed by a prolonged after-hyperpolarization. These discharges are believed to contribute to the paroxysmal depolarization shifts and afterhyperpolarization in experimental epileptic foci. ${ }^{51}$

Neurons are influenced by synaptic and nonsynaptic interconnections. Neurochemical transmission between neurons involves a number of steps that can be selectively altered to affect neuronal excitability. These steps result in the release of neurotransmitters into the synaptic cleft and the postsynaptic membrane, resulting in excitatory or inhibitory postsynaptic potentials via $\mathrm{Ca}^{2+}$ and other second messengers. ${ }^{52}$ The transmitters are deactivated by enzymes, by reuptake into axon terminals, or by uptake by glia. The primary excitatory neurotransmitters in the central nervous system are the amino acids glutamate and aspartate. The primary inhibitory neurotransmitters in the central nervous system are gamma-aminobutyric acid (GABA) and glycine. Neurotransmitters and neuromodulators exert their effects by acting on receptors. ${ }^{53}$ Specific properties of receptors have been identified on the basis of the effects of certain agonist and antagonist agents, some of which are anticonvulsant drugs. $\mathrm{GABA}_{\mathrm{A}}$ receptor drugs, which activate $\mathrm{Cl}^{-}$, appear to be more effective as anticonvulsants than $\mathrm{GABA}_{\mathrm{B}}$ receptor agents, which activate $\mathrm{K}^{+}$. The 
$\mathrm{GABA}_{\mathrm{A}}$ receptor is of primary importance in absence epilepsy due to its role in the synchronization and desynchronization of thalamocortical pathways. ${ }^{54}$ The oscillatory and burst-firing of these circuits is attributed to neurons in the reticular nucleus of the thalamus and leads to synchronization and desynchronization of the electroencephalogram (EEG). Alterations of this mechanism produce absence seizures. Kainic acid, quisqualic acid, and $N$ methyl-d-aspartate (NMDA) are excitatory amino acid analogues used to define the classes of receptors responsive to glutamate and aspartate. NMDA antagonists are one potential mechanism for some of the anticonvulsants. ${ }^{55}$

Two hypotheses are associated with cortical dysplasia, which is a frequent cause of medically intractable focal epilepsy. The first hypothesis suggests that epileptogenesis results from a change in the synaptic properties of interneurons. The second hypothesis suggests abnormal intrinsic properties in the neurons, such as a mutation in the ion channel. ${ }^{56}$

\subsection{Signs and symptoms}

There have been many attempts at a classification system for epileptic seizures. The most widely used classification system is the one developed by the International League against Epilepsy (ILAE), which is an electroclinical classification system (Table $3){ }^{57}$ This classification assumes that there is a oneto-one correlation between the phenomenology of the actual seizures and electrical abnormalities on the EEG seen with the seizure. This, however, is not always the case and these exceptions highlight the main weakness of the ILAE classification.

Table 3. International League Against Epilepsy Classification of Epileptic Seizures

\begin{tabular}{ll}
\hline Seizure Types & Features \\
\hline Partial Seizures & EEG findings suggest focal onset \\
Simple Partial Seizures & Consciousness not impaired \\
Phonatory & Vocalization arrest of speech \\
With somatosensory or special sensory symptoms & Simple hallucinations \\
With autonomic symptoms or signs & Epigastric sensations, pallor, sweating, flushing, \\
& piloerection, pupillary dilation \\
With psychic symptoms & Disturbance of higher cortical function \\
Complex partial seizures & Consciousness impaired \\
Typical absence & Regular and symmetrical 3-Hz SWC on EEG \\
Atypical absence & Irregular slow SWC on EEG \\
Myoclonic Seizures & Polyspike or slow SWC on EEG \\
Clonic Seizures & Fast activity or slow SWC on EEG \\
Tonic Seizures & Low-voltage fast EEG \\
Tonic-Clonic Seizures & Rhythm of less than 10 Hz on EEG \\
Atonic Seizures & Poly SWC or low-voltage fast \\
\hline
\end{tabular}

\subsection{Treatment}

The first-line treatment of epilepsy is the administration of an antiepileptic drug (AED). The selection of an appropriate AED is based on a diagnosis of the epileptic syndrome of the patient (Table 4). First-line therapy for patients with focal seizures includes phenytoin, carbamazepine, and valproate. Drugs for adjunctive therapy for focal seizures include levetiracetam, topiramate, zonisamide, lamotrigine, gabapentin, oxcarbazepine, phenobarbital, and tiagabine. Drugs used in generalized seizures include valproate, lamotrigine, phenytoin, phenobarbital, and ethosuximide, which is specific for absence seizures. ${ }^{58}$ 

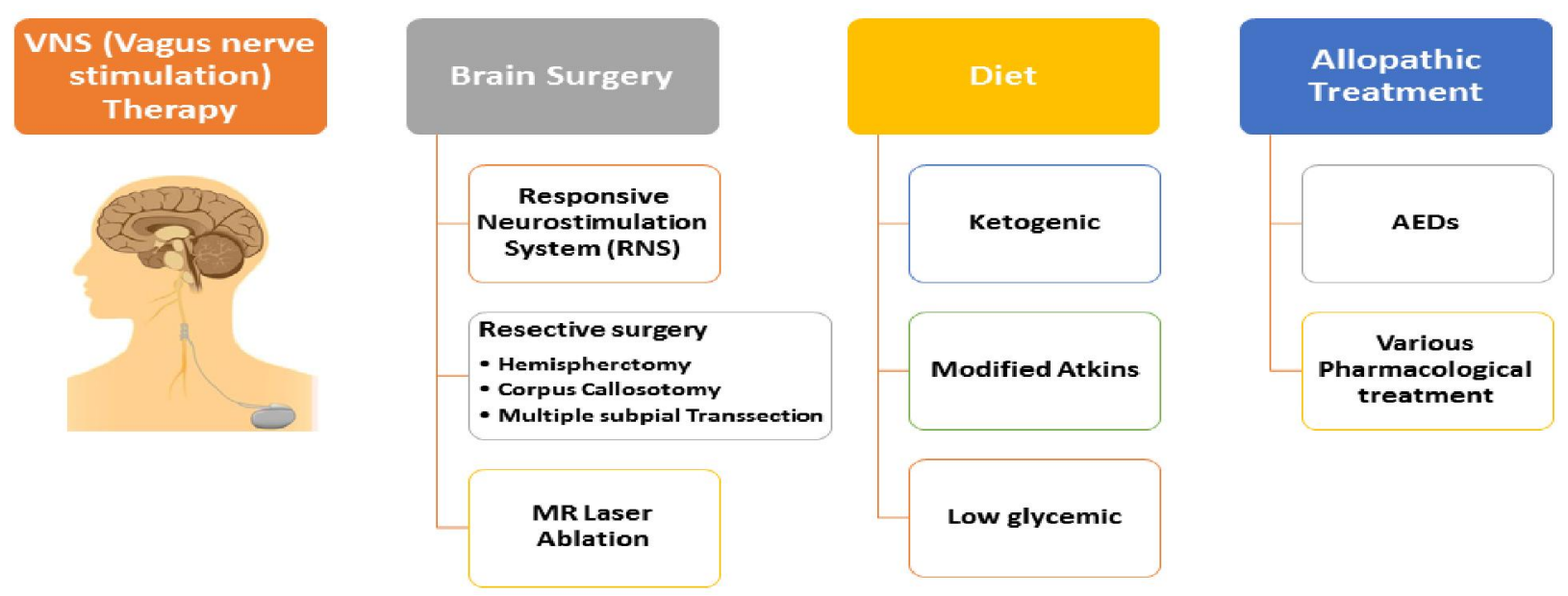

Figure 3. Treatment alternatives for Drug resistant Epilepsy

Table 2. Characteristics of Various Antiepileptic Drugs (AEDs)

\begin{tabular}{|c|c|c|c|}
\hline AED & Efficacy & Dose & Side effects \\
\hline Carbamazepine & $\begin{array}{l}\text { Partial seizures, } \\
\text { generalized } \\
\text { seizures }\end{array}$ & $\begin{array}{l}200 \mathrm{mg} / \text { day at } 1-\mathrm{wk} \\
\text { intervals }\end{array}$ & $\begin{array}{l}\text { Neurocognitive effects, rash, nausea, } \\
\text { vomiting, hyponatremia }\end{array}$ \\
\hline Ethosuximide & Absence seizures & $\begin{array}{l}250 \mathrm{mg} / \text { day at } 1-w \mathrm{k} \\
\text { intervals }\end{array}$ & $\begin{array}{l}\text { Neurocognitive effects, anorexia, } \\
\text { nausea, vomiting, weight loss, } \\
\text { diarrhea, abdominal pain, headache, } \\
\text { mood changes, rash, hirsutism, and } \\
\text { gingival hyperplasia }\end{array}$ \\
\hline Gabapentin & Partial seizures & $\begin{array}{l}300 \mathrm{mg} / \text { day at } 24-\mathrm{hr} \\
\text { intervals }\end{array}$ & $\begin{array}{l}\text { Neurocognitive effects, weight gain, } \\
\text { mood changes, dry mouth, } \\
\text { periorbital edema, myalgias }\end{array}$ \\
\hline Lacosamide & Partial seizures & $\begin{array}{l}100 \mathrm{mg} / \text { day at } 1-w k \\
\text { intervals }\end{array}$ & $\begin{array}{l}\text { Neurocognitive, nausea, vomiting, } \\
\text { cardiac conduction abnormalities }\end{array}$ \\
\hline Lamotrigine & $\begin{array}{l}\text { Generalized and } \\
\text { partial seizures }\end{array}$ & $\begin{array}{l}50 \mathrm{mg} / \text { day at } 2-w k \\
\text { intervals }\end{array}$ & $\begin{array}{l}\text { Neurocognitive effects, headache, } \\
\text { rash, mood changes, nausea, } \\
\text { vomiting }\end{array}$ \\
\hline Levetiracetam & Partial seizures & $\begin{array}{l}1000 \mathrm{mg} / \text { day at } 2- \\
\text { wk intervals }\end{array}$ & $\begin{array}{l}\text { Neurocognitive effects, mood } \\
\text { changes, behavior } \\
\text { anesthesia }\end{array}$ \\
\hline Oxcarbazepine & Partial seizures & $\begin{array}{l}600 \mathrm{mg} / \text { day at } 1-\mathrm{wk} \\
\text { intervals }\end{array}$ & $\begin{array}{l}\text { Neurocognitive effects, rash, nausea, } \\
\text { vomiting, hyponatremia }\end{array}$ \\
\hline Phenobarbital & $\begin{array}{l}\text { Generalized and } \\
\text { partial seizures }\end{array}$ & $\begin{array}{l}30 \mathrm{mg} / \text { day at } 4-w \mathrm{k} \\
\text { intervals }\end{array}$ & $\begin{array}{l}\text { Neurocognitive effects, mood } \\
\text { changes, nausea, vomiting, rash, } \\
\text { porphyria exacerbation, physical } \\
\text { dependence }\end{array}$ \\
\hline Phenytoin & $\begin{array}{l}\text { Generalized and } \\
\text { partial seizures }\end{array}$ & $\begin{array}{l}100 \mathrm{mg} / \text { day at } 4-\mathrm{wk} \\
\text { intervals }\end{array}$ & $\begin{array}{l}\text { Neurocognitive effects, hirsutism, } \\
\text { gingival hyperplasia, nausea, } \\
\text { vomiting, coarse facies, headache, } \\
\text { lymphadenopathy, osteomalacia }\end{array}$ \\
\hline Pregabalin & Partial seizures & $150 \mathrm{mg} /$ day at $1-w \mathrm{k}$ & Neurocognitive effects, weight gain, \\
\hline
\end{tabular}




\begin{tabular}{|c|c|c|c|}
\hline & & intervals & peripheral edema \\
\hline Tiagabine & Partial seizures & $\begin{array}{l}4-8 \mathrm{mg} / \text { day at } 1-w k \\
\text { intervals }\end{array}$ & $\begin{array}{l}\text { Neurocognitive effects, mood } \\
\text { changes, asthenia, nausea, vomiting }\end{array}$ \\
\hline Topiramate & $\begin{array}{l}\text { Generalized and } \\
\text { partial seizures }\end{array}$ & $\begin{array}{l}25-50 \mathrm{mg} / \text { day at } 1- \\
\text { wk intervals }\end{array}$ & $\begin{array}{l}\text { Neurocognitive effects, language } \\
\text { problems, psychomotor slowing, } \\
\text { mood changes, paresthesia, weight } \\
\text { loss, renal stones }\end{array}$ \\
\hline Valproate & $\begin{array}{l}\text { Generalized and } \\
\text { partial seizures }\end{array}$ & $\begin{array}{l}250 \mathrm{mg} / \text { day at } 1-\mathrm{wk} \\
\text { intervals }\end{array}$ & $\begin{array}{l}\text { Neurocognitive effects, weight gain, } \\
\text { nausea, vomiting, headache, hair } \\
\text { loss, menstrual irregularities }\end{array}$ \\
\hline Zonisamide & Partial seizures & $\begin{array}{l}100 \mathrm{mg} / \text { day at } 2-\mathrm{wk} \\
\text { intervals }\end{array}$ & $\begin{array}{l}\text { Neurocognitive effects, } \\
\text { changes, insomnia }\end{array}$ \\
\hline
\end{tabular}

In patients who do not respond to medication, epilepsy surgery is a potential mode of treatment that can offer up to a $70 \%$ to $90 \%$ chance of seizure freedom (defined as no seizures or auras only, on medication) in some patients. Other novel modes of therapy include the vagal nerve stimulator (VNS), which is usually reserved for those patients with intractable epilepsy who are not surgical candidates. The VNS usually is as effective as a typical AED and usually does not provide a seizure-free state. Its mechanism of action is not known. The benefits of the VNS, as opposed to AEDs, is that it does not have the neurotoxicities associated with AEDs. Some adverse effects of the VNS include coughing, hoarse

\section{REFERENCES}

1. Carstairs GM, Kapur RL. The great universe of Kota: Stress change and mental disorder in an Indian village: University of California Pr; 1976.

2. Halliburton M. Finding a fit: psychiatric pluralism in south India and its implications for WHO studies of mental disorder. Transcultural psychiatry 2004;41(1):80-98.

3. Alzheimer's Disease Fact Sheet. In. United state of America: National Institutes of Aging; 2016.

4. Population Ageing-A Public Health Challenge. In: Fact Sheet. Geneva: World Health Organization 1998.

5. Santhosh NS, Sinha S, Satishchandra P. Epilepsy: Indian perspective. Annals of Indian Academy of Neurology 2014;17(Suppl 1):S3-S11.

6. Kessler RC, McGonagle KA, Zhao S, Nelson CB, Hughes M, Eshleman S, et al. Lifetime and 12-month prevalence of DSM-III-R psychiatric disorders in the United States. Results from the voice, bradycardia, and exacerbation of sleep apnea. Neurocognitive side effects include dizziness, drowsiness, unsteadiness, blurred vision, ataxia, tremor, nystagmus, impaired memory, and fatigue. ${ }^{59}$

\section{CONCLUSION}

Allopathic drugs are effective but at the cost of serious side effects, which needs a special attention towards the alternative medicinal system. Nowadays Naturopathy is considered as the safest and effective system towards the brain diseases and disorders. A sufficient research should conduct to enhance the use of natural drug therapy towards the Pschycopharmcological disorders.

National Comorbidity Survey. Arch Gen Psychiatry 1994;51(1):8-19.

7. Kessler RC, Berglund P, Demler O, Jin R, Koretz D, Merikangas KR, et al. The epidemiology of major depressive disorder: results from the National Comorbidity Survey Replication (NCS-R). Jama 2003;289(23):3095-105.

8. Keller MB, Hirschfeld R, Hanks D. Double depression: a distinctive subtype of unipolar depression. Journal of affective disorders 1997;45(12):65-73.

9. Angst J. How recurrent and predictable is depressive illness. Long-term treatment of depression. Chichester: Wiley 1992:1-14.

10. Wong M-L, Licinio J. Research and treatment approaches to depression. Nature Reviews Neuroscience 2001;2(5):343-351.

11. Schildkraut JJ. The catecholamine hypothesis of affective disorders: a review of 
supporting evidence. The American journal of psychiatry 1965.

12. Stahl SM. Basic psychopharmacology of antidepressants: Part 1. Antidepressants have seven distinct mechanisms of action. Journal of Clinical Psychiatry 1998.

13. Price LH, Charney DS, Delgado PL, Heninger GR. Lithium and serotonin function: implications for the serotonin hypothesis of depression. Psychopharmacology 1990;100(1):3-12.

14. Rubin RT, Poland RE, Lesser IM, Martin DJ. Neuroendocrine aspects of primary endogenous depression. V. Serum prolactin measures in patients and matched control subjects. Biological psychiatry 1989;25(1):4-21.

15. Holsboer F. The corticosteroid receptor hypothesis of depression. Neuropsychopharmacology 2000;23(5):477-501.

16. Sternberg EM. Emotions and disease: from balance of humors to balance of molecules. Nature medicine 1997;3(3):264-267.

17. Connor TJ, Leonard BE. Depression, stress and immunological activation: the role of cytokines in depressive disorders. Life sciences 1998;62(7):583-606.

18. Duman RS, Malberg J, Thome J. Neural plasticity to stress and antidepressant treatment. Biological psychiatry 1999;46(9):1181-1191.

19. Altar CA. Neurotrophins and depression. Trends in pharmacological sciences 1999;20(2):5962.

20. American Psychiatric A. Diagnostic and statistical manual of mental disorders: DSM-IVTRÂ®: American Psychiatric Pub; 2000.

21. Feighner JP. Mechanism of action of antidepressant medications. In: Assessing Antidepressant Efficacy: A Reexamination., Jan, 1998, Phoenix, AZ, US; 1999: Physicians Postgraduate Press; 1999.

22. Glassman AH, Shapiro PA. Depression and the course of coronary artery disease. American Journal of Psychiatry 1998;155(1):4-11.

23. Murphy DL, Andrews AM, Wichems $\mathrm{CH}$, Li Q, Tohda M, Greenberg B. Brain serotonin neurotransmission: An overview and update with an emphasis $\mathrm{n}$ serotonin subsystem heterogeneity, multiple receptors, interactions with other neurotransmitter systems, and consequent implications for understanding the actions of serotonergic drugs. Journal of Clinical Psychiatry 1998.

24. McEwen BS, Conrad CD, Kuroda Y, Frankfurt M, Maria Magarinos A, McKittrick C. Prevention of stress-induced morphological and cognitive consequences. European Neuropsychopharmacology 1997;7:S323-S328.

25. Creutzfeldt HG. Ãœber eine eigenartige herdfÃ $\mid$ rmige Erkrankung des Zentralnervensystems (vorlãăufige Mitteilung). Zeitschrift f $\tilde{A}^{1} 1 / 4 \mathrm{r}$ die gesamte Neurologie und Psychiatrie 1920;57(1):1-18. 26. Dubois B, Feldman HH, Jacova C, DeKosky ST, Barberger-Gateau P, Cummings J, et al. Research criteria for the diagnosis of Alzheimer's disease: revising the NINCDSâ€"ADRDA criteria. The Lancet Neurology 2007;6(8):734-746.

27. Swartz RH, Black SE, George-Hyslop PS. Apolipoproteine and Alzheimer's disease: A genetic, molecular and neuroimaging review. The Canadian Journal of Neurological Sciences 1999;26(2):77-88.

28. Cummings JL, Vinters HV, Cole GM, Khachaturian ZS. Alzheimer's disease Etiologies, pathophysiology, cognitive reserve, and treatment opportunities. Neurology 1998;51(1 Suppl 1):S2-S17. 29. Arriagada PV, Growdon JH, Hedley-Whyte ET, Hyman BT. Neurofibrillary tangles but not senile plaques parallel duration and severity of Alzheimer's disease. Neurology 1992;42(3):631-631.

30. Coleman PD, Yao PJ. Synaptic slaughter in Alzheimerâ€ $€^{\mathrm{TM}_{\mathrm{S}}}$ disease. Neurobiology of aging 2003;24(8):1023-1027.

31. Whitehouse PJ, Price DL, Clark AW, Coyle JT, DeLong MR. Alzheimer disease: evidence for selective loss of cholinergic neurons in the nucleus basalis. Annals of neurology 1981;10(2):122-126.

32. DeKosky ST. Monoamine neurons in aging and Alzheimer's disease. Journal of Neural Transmission/General Section JNT 1993;91(23):135-159.

33. Bird T. Clinical genetics of familial Alzheimer's disease. In: Terry R, Katzman R, Bick K, editors. Alzheimer Disease. New York: Raven Press; 1994. p. 65-74.

34. Jones RW. Inflammation and Alzheimer's disease. The Lancet 2001;358(9280):436-437.

35. Veld BA, Ruitenberg A, Hofman A, Launer LJ, van Duijn CM, Stijnen T, et al. Nonsteroidal antiinflammatory drugs and the risk of Alzheimer's 
disease. New England Journal of Medicine 2001;345(21):1515-1521.

36. Aisen PS, Schafer KA, Grundman M, Pfeiffer E, Sano M, Davis KL, et al. Effects of rofecoxib or naproxen vs placebo on Alzheimer disease progression. JAMA: the journal of the American Medical Association 2003;289(21):28192826.

37. Tarawneh R, Holtzman DM. The Clinical Problem of Symptomatic Alzheimer Disease and Mild Cognitive Impairment. Cold Spring Harbor Perspectives in Medicine 2012;2(5):a006148.

38. Cerejeira J, Lagarto L, Mukaetova-Ladinska EB. Behavioral and Psychological Symptoms of Dementia. Frontiers in Neurology 2012;3:73.

39. Leehey MA. Fragile X-associated Tremor/Ataxia Syndrome (FXTAS): Clinical Phenotype, Diagnosis and Treatment. Journal of investigative medicine : the official publication of the American Federation for Clinical Research 2009;57(8):830-836.

40. Jinny T, Patrick S. Alzheimer's Disease. In. Beachwood, Ohio: Cleveland Clinic Center 2010.

41. Parsons CG, Danysz W, Dekundy A, Pulte I. Memantine and Cholinesterase Inhibitors: Complementary Mechanisms in the Treatment of Alzheimer's Disease. Neurotoxicity Research 2013;24(3):358-369.

42. Casey DA, Antimisiaris D, O’Brien J. Drugs for Alzheimer's Disease: Are They Effective? Pharmacy and Therapeutics 2010;35(4):208-211.

43. Sano M, Ernesto C, Thomas RG, Klauber MR, Schafer K, Grundman M, et al. A controlled trial of selegiline, alpha-tocopherol, or both as treatment for Alzheimer's disease. New England Journal of Medicine 1997;336(17):1216-1222.

44. Fisher RS, Harding G, Erba G, Barkley GL, Wilkins A. Photic- and Pattern-induced Seizures: A Review for the Epilepsy Foundation of America Working Group. Epilepsia 2005;46(9):1426-1441.

45. Nair D. Epilepsy. In. Beachwood, Ohio: Cleveland Clinic Center 2010.

46. Engel J. Seizures and epilepsy: Oxford University Press.

47. Dubyak GR. Ion homeostasis, channels, and transporters: an update on cellular mechanisms.
Advances in Physiology Education 2004;28(4):143154.

48. Morgan JI, Cohen DR, Hempstead JL, Curran T. Mapping patterns of c-fos expression in the central nervous system after seizure. Science 1987;237(4811):192-197.

49. The Petilla Interneuron Nomenclature G. Petilla terminology: nomenclature of features of GABAergic interneurons of the cerebral cortex. Nature reviews. Neuroscience 2008;9(7):557-568.

50. Messenheimer JA, Harris EW, Steward O. Sprouting fibers gain access to circuitry transsynaptically altered by kindling. Experimental neurology 1979;64(3):469-481.

51. Matsumoto H, Marsan CA. Cortical cellular phenomena in experimental epilepsy: interictal manifestations. Experimental neurology 1964;9(4):286-304.

52. Cheung G, Sibille J, \#xe9, \#xe9, mie, Zapata $\mathrm{J}$, et al. Activity-Dependent Plasticity of Astroglial Potassium and Glutamate Clearance. Neural Plasticity 2015;2015:16.

53. Neurotransmitters as the Chemical Messengers of Certain Circuits and Pathways. In: The Human Nervous System: Structure and Function. Totowa, NJ: Humana Press; 2005. p. 267-283.

54. Löscher W, Rogawski MA. How theories evolved concerning the mechanism of action of barbiturates. Epilepsia 2012;53:12-25.

55. Huguenard JR. Neuronal circuitry of thalamocortical epilepsy and mechanisms of antiabsence drug action. Adv Neurol 1999;79:991-9.

56. Baraban SC. Epileptogenesis in the Dysplastic Brain: A Revival of Familiar Themes. Epilepsy Currents 2001;1(1):6-11.

57. Angeles DKF. Proposal for revised clinical and electroencephalographic classification of epileptic seizures. Epilepsia 1981;22489(501).

58. Goldenberg MM. Overview of Drugs Used For Epilepsy and Seizures: Etiology, Diagnosis, and Treatment. Pharmacy and Therapeutics 2010;35(7):392-415.

59. Kwan P, Sperling MR. Refractory seizures: try additional antiepileptic drugs (after two have failed) or go directly to early surgery evaluation? Epilepsia 2009;50 Suppl 8:57-62. 